\title{
Effect of introduction of fullerene soot on mechanical properties of unidirectional thermoplastic tape
}

\author{
Ilya Kobykhno ${ }^{1, *}$, Dmytro Honcharenko ${ }^{1}$, Vladimir Yadykin $^{1}$, Oleg Stolyarov ${ }^{1}$, and Oleg \\ Tolochko ${ }^{1}$ \\ ${ }^{1}$ Peter the Great St. Petersburg Polytechnic University, Polytechnicheskaya 29, St. Petersburg, 195251, \\ Russian Federation
}

\begin{abstract}
A series of unidirectional thermoplastic tapes (UD tapes) specimens based on carbon fibers and polyamide filled with fullerene soot in a concentration of up to $4 \mathrm{wt}$. \% was made. From the obtained tapes by the method of hot pressing, composite materials (CM) specimens with $0 / 0$ and $90 / 90$ ply orientations were made. A study of the mechanical properties of the samples obtained by the 3-point bending test was made. Shown that the introduction of fullerene soot up to 2 wt. \% can significantly increase the strength and modulus of elasticity of both longitudinal and transverse reinforcement directions. Further increase in the concentration of soot leads to a decrease in properties. A theory that describes the effect of fullerene soot on the properties of $\mathrm{CM}$, including the increase and further decrease in properties, depending on the concentration of nanoparticles was proposed.
\end{abstract}

\section{Introduction}

Fiber reinforced polymers (FRP) filled with unidirectional fibers are increasingly used as structural materials. Their main advantage is high specific strength and rigidity, corrosion resistance, resistance to fatigue, as well as the ability to optimize the geometry of the product with a complex stress-strain state due to flexible manufacturing methods.

There are two types of polymer materials used as matrices in FRP: thermosetting and thermoplastic. Thermoset polymers, such as epoxy, phenolic and polyester resins, have a fully crosslinked molecular structure and cannot be recycled after curing. Thermoplastic polymers such as polyamide, polypropylene, polyphenylene sulfide and polyetheretherketone do not have a crosslinked molecular structure and can be recycled by melting. Main advantages of FRP based on thermoplastic polymers are [1]:

1. Increased mechanical properties;

2. Increased resistance to environment;

3. Practically unlimited shelf life of raw materials;

4. Manufacturing process can be adapted consider to the design features of the final product (including the possibility of manufacturing of final product by additive technologies);

5. Environmental safety (both at the manufacturing and at the processing stage);

\footnotetext{
* Corresponding author: ilya.kobykhno.gmail.com
} 
6. Faster manufacturing of the final product;

7. The ability to mold large integrated complex moldings in one operation

Initially, the introduction of FRP based on thermoplastic polymers began with the use of woven prepregs and sheets (up to a few mm thick) made using carbon fibers. These materials have high performance characteristics, and found wide application in the automotive industry. However, during manufacture of parts with complex geometry, there is a need for cutting the workpiece. Depending on the complexity of the workpiece, the use of this materials leads to a loss of 25 to $30 \%$ of the material at the cutting stage. As an alternative to this solution, it has been proposed to use UD tapes. Such tapes are a prepreg sheet with a thickness of up to $0.35 \mathrm{~mm}$ and a width of 5 to $250 \mathrm{~mm}$, in which all reinforcing fibers are located along the longitudinal axis. By the using of modern processing methods (Automated Fiber Placement (AFP) and Automated Tape Laying (ATL)), it is possible to optimize the geometry of the workpiece to reduce material loss. In present, this class of FRP has a great interest to researchers and finds more and more industrial applications [2-6].

In paper [7], the main methods for the manufacturing of unidirectional composite tapes based on thermoplastic polymers were described: solution processing, slurry processing, melt impregnation, film stacking, fiber co-mingling, dry powder impregnation.

Slurry processing has a great potential for industrial applications, since it is environmentally friendly, inflict minimal damage to the fiber, and it also allows high equipment productivity of the. In papers $[8,9]$, the manufacturing processes of FRP by this method were described in detail. Also, in paper [10], a mathematical model of process of polymer powder introduction and sintering was proposed, using the dry impregnation method as an example. It can also be used to develop an industrial technology for tape manufacturing by the slurry processing.

Due to the fact that composite materials consist of several phases with a clearly discernible boundary, the strength and rigidity of this class of materials depends on the strength of interfacial bonding, adhesion, which through the matrix ensures the redistribution of the load between the fibers. Consequently, the ability to control and regulate adhesion in FRP makes it possible to produce a higher quality material (with increased physicomechanical characteristics) [11].

There are two main approaches to increase the adhesion between the matrix and reinforcement: fiber surface treatment (chemical or physical) and the manufacturing of "Multiscale composite", in which nanoparticles of different nature (carbon, oxide, etc.) are additionally introduced into the matrix [12-14].

It was shown in [15-17] that the introduction of carbon nanoparticles of different nature into glue mixture based on epoxy resins gives an increase in the shear strength of the adhesive compound with metals. Also, in papers [18-20] it was shown that the introduction of carbon nanotubes in FRP increases the adhesion of the fiber to the matrix and the mechanical properties of CM [21-27].

The aim of this work is to study the effect of introducing fullerene soot particles into the polymer matrix on the mechanical characteristics of unidirectional tapes based on thermoplastic polymer and carbon fibers.

\section{Materials and methods}

\subsection{Materials}

The carbon fiber SYT49 12K (Zhongfu Shenying Carbon Fiber Co., Ltd) was used for manufacturing unidirectional thermoplastic tapes. As a polymer matrix, the powdered polyamide Innova'PA 1550 (Exceltec Ltd.) was used with an average particle size of 40-50 
$\mu \mathrm{m}, \mathrm{T}_{\mathrm{m}}=185^{\circ} \mathrm{C}$. To obtain a stable suspension, a surfactant, sodium lauryl sulfate, was used. To obtain the nanocomposite material, fullerene soot (Suzhou Dade Carbon Nanotechnology Co.) was used.

\subsection{Composite tape manufacturing equipment}

To manufacture the composite tape a pultrusion equipment based on slurry process was developed.

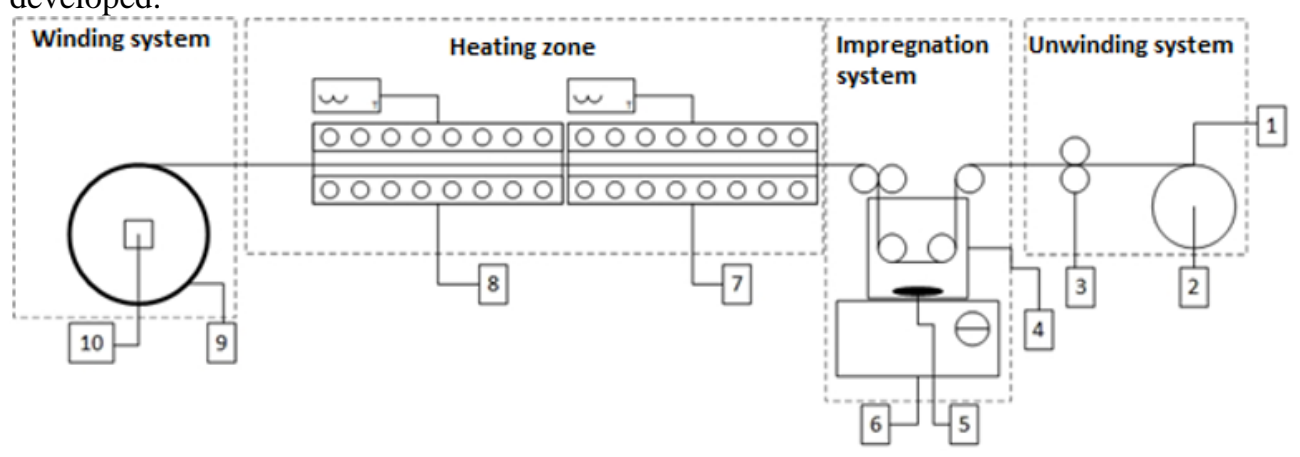

Fig. 1. Schematic diagram of the developed pultrusion equipment

Fig. 1 shows schematic diagrams of a pultrusion equipment. The equipment consists of 4 main units: unwinding, impregnating, heating and winding. The equipment works according to the following principle: the carbon thread (1) is unwound from the spool (2) and passes through the thread twist control system (3). Then, the carbon filament enters the impregnation bath (4), in which the suspension of the polymer powder is located. The stability of the suspension is maintained by means of a magnetic stirrer (5) driven by a drive (6). In the heating unit, the carbon fiber coated with the polymer slurry passes through a drying oven (7), at a temperature of $120-130^{\circ} \mathrm{C}$ (400 mm long), and then through a sintering furnace (8) (400 $\mathrm{mm}$ long), the temperature in which depends on the polymer binder type. The finished composite tape reels on the spool (9) using the drive (10). This design of the plant provides the manufacturing speed up to $500 \mathrm{~mm} / \mathrm{min}$, depending on the type of polymer powder (melting point and average particle size). The maximum productivity of the equipment is largely limited by the length and efficiency of the furnaces.

\subsection{Methods}

The manufactured tape structure was studied using an optical microscope Carl Zeiss Observer D1m. A study of the mechanical properties of composite materials was carried out using the 3 -point bending test method with the universal testing machine Instron 5965. The traverse speed was $1 \mathrm{~mm} / \mathrm{min}$, support span-to-depth ratio was 1:32.

\section{Results and discussion}

To introduce carbon nanoparticles into the volume of the material, they were initially mixed with a polymer powder and a surfactant. Mixing was done in "drunk barrel" mills, in a glass beaker using glass balls. To obtain a stable suspension, the surfactant concentration in the polymer was $1 \mathrm{wt}$. $\%$. The fullerene soot concentration in the polymer was $1 ; 2 ;$ and $4 \mathrm{wt} . \%$.

Figure 2 shows microsection of manufactured UD tapes. There are no pores in polymer and defects at the fiber-polymer interface, which indicates a qualitative impregnation, good 
wetting, and sintering of the polymer on the fiber surface. The tape surface has a ripples and roughness, which is due to the fact that the tape does not undergo an additional calendering stage.

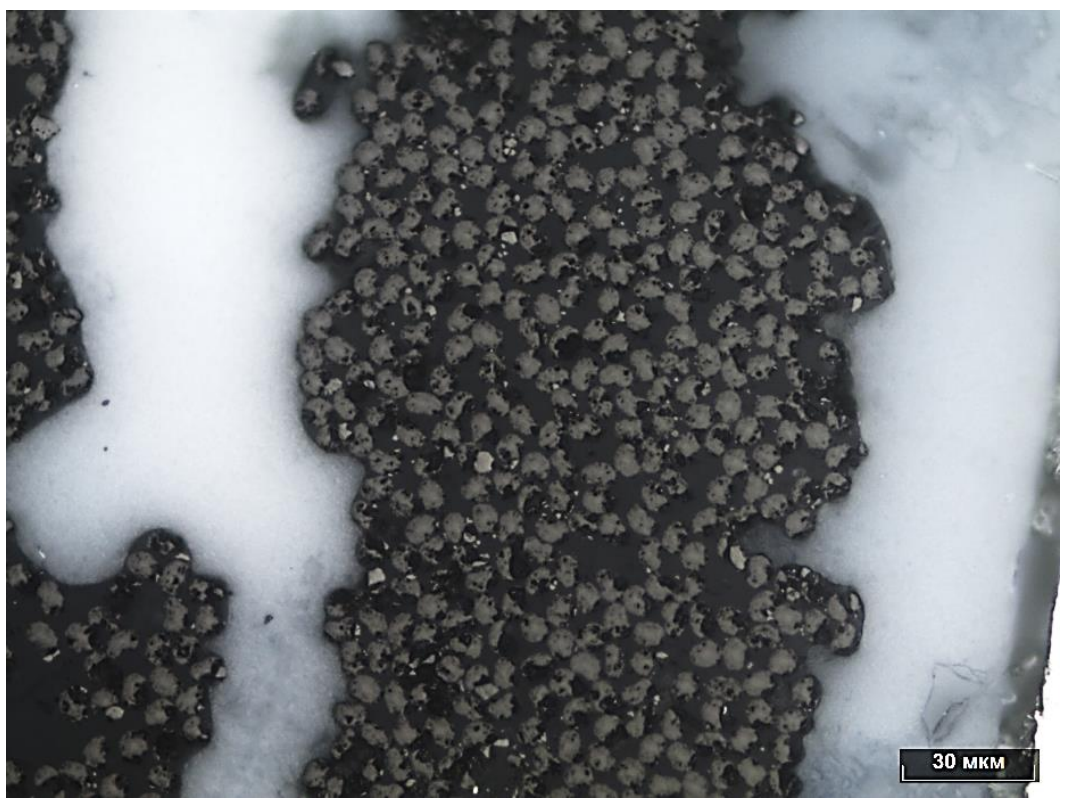

Fig. 2. Microsection of manufactured UD tapes.

To manufacture CM specimens for testing, the hot pressing method was used. Tape pieces were stacked one after the other to obtain a specimen with reinforcement along one axis. The pressing was carried out at a temperature of $220^{\circ} \mathrm{C}$ and a pressure of $10 \mathrm{MPa}$. Manufactured specimens had a length of $90 \mathrm{~mm}$, a width of $45 \mathrm{~mm}$ and a thickness of 1.4-1.6 mm. Two types of specimens were manufactured, longitudinally (with a side size of $90 \mathrm{~mm}$ ) and transversely reinforced.

Figure 3 shows the curves of the CM specimens with different content of fullerene soot in longitudinal (a) and transverse (b) specimens.

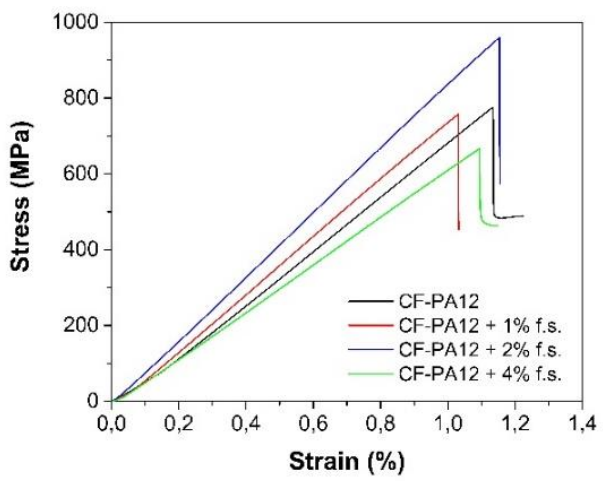

a)

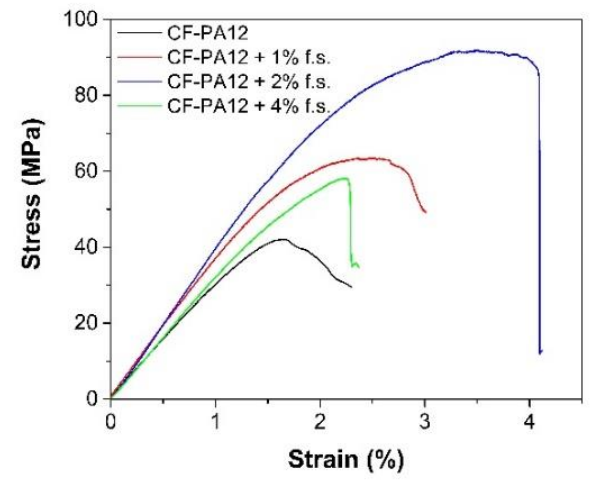

b)

Fig.3. 3-point bending test of longitudinal $(a)$ and transverse $(b)$ specimens. 
Figure 4 shows the relation between the ultimate flexural strength (UFS) and modulus of elasticity of the CM as a function of the concentration of fullerene soot in the polymer in longitudinal (a) and transverse (b) specimens.

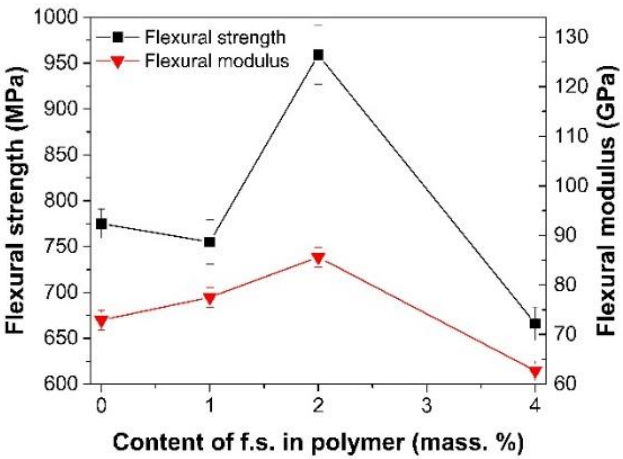

a)



b)

Fig.4. Relation of the UFS and modulus of elasticity between the concentration of fullerene soot: in longitudinal (a) and transverse (b) specimens.

Composite materials manufactured from UD tapes without fullerene soot have the next values: $\sigma_{\mathrm{UFS}}=775 \pm 16 \mathrm{MPa}$ and $\mathrm{E}=72.9 \pm 2 \mathrm{GPa}$ in longitudinal specimens and $\sigma_{\mathrm{UFS}}=42$ $\pm 4 \mathrm{MPa}$ and $\mathrm{E}=2.84 \pm 0.2 \mathrm{MPa}$ in transverse specimens.

The introduction of fullerene soot into the polymer matrix in the amount of $1 \mathrm{wt} . \%$ leads to an insignificant increase in the modulus of elasticity in longitudinal test, while the value of the strength remains in the limit of the static error. By increase the concentration of carbon black to 2 wt. $\%$ occurs a significant increase in the tensile strength, by $20 \%$, and the modulus of elasticity, by $15 \%$. Further increase in the soot content, up to $4 \mathrm{wt}$. $\%$ leads to a decrease in mechanical characteristics to values below the basic CM (non-filled with nanoparticles).

Analysis of the results obtained in a transverse test, demonstrates that $1 \mathrm{wt} \%$ of the carbon black increases the ultimate strength by $33 \%$ and the modulus of elasticity by $18 \%$. When the concentration of carbon black is 2 mass. \%, the strength limit is increased by $116 \%$ and the modulus of elasticity by $32 \%$, compared with the original CM. A further increase in the concentration of soot to $4 \mathrm{wt}$. \%, as well as in the longitudinal test, leads to a decrease in the mechanical characteristics of the $\mathrm{CM}$, but their values still exceed the analogous values for the initial CM.

The observed effect of a gradual increase in the mechanical properties of CM with an increase in the concentration of nanoparticles to a threshold value and their subsequent decrease, can be explained by the presence of two competing mechanisms. The first mechanism is associated with an increase in the adhesive strength between the polymer and carbon fibers initiated by nanoparticles of fullerene soot. The second mechanism is associated with a decrease in the cohesive strength of the polymer matrix as a result of introduced nanoparticles. In the first stage (when a carbon black is added to $2 \%$ by mass), the increase in the adhesive strength between the components occurs more intensively than the decrease in the cohesive strength of the polymer. A further increase in the concentration of nanoparticles leads to such a significant decrease in the cohesive strength of the polymer, which leads to a decrease in the strength characteristics of the entire composite material.

The results of the transverse test are in favor of this theory, since the main contribution to the value of the ultimate strength and modulus of elasticity in this axis is made by the adhesive interaction between the fiber and the matrix. 


\section{Conclusions}

The method of manufacturing unidirectional composite tapes based on thermoplastic polymers filled with carbon nanoparticles was demonstrated.

The mechanical properties of the manufactured materials, both longitudinal and transverse, were studied by the 3-point bending test.

The influence of the introduction of fullerene soot on the strength characteristics of CM is shown. It was found that with the introduction of $2 \mathrm{wt}$. \% of nanoparticles, the greatest increase in the tensile strength and modulus of elasticity is achieved, both longitudinal and transverse directions. A further increase in the concentration of soot leads to a decrease of the properties down to values lower than those of the basic material.

A theory is proposed that explains the behavior of the system as a function of the concentration of soot, including the increase and subsequent decrease in properties.

\section{References}

1. U.K. Vaidya, K.K. Chawla, Int. Mater. Rev., 53, 185-218 (2008).

2. M. Kropka, M. Muehlbacher, T. Neumeyer, V. Altstaedt, Procedia CIRP, 66, 96-100 (2017).

3. A. Margossian, S. Bel, R. Hinterhoelzl, Compos. Part A Appl. Sci. Manuf., 77, 154-163 (2015).

4. T. Yamamoto, K. Hayakawa, Procedia Manuf., 15, 1708-1715 (2018).

5. D. Dörr, W. Brymerski, S. Ropers, D. Leutz, T. Joppich, L. Kärger, F. Henning, Procedia CIRP, 66, 101-106 (2017).

6. A. Margossian, S. Bel, Hinterhoelzl, R. Compos. Part A Appl. Sci. Manuf., 88, 48-58 (2016).

7. S.R. Iyer, L.T. Drzal, J. Thermoplast. Compos. Mater., 3, 325-355 (1990).

8. A.M. Vodermayer, J.C. Kaerger, G. Hinrichsen, Compos. Manuf., 4, 123-132 (1993).

9. K. Ramani, C. Hoyle, Mater. Manuf. Process., 10, 1169-1182 (1995).

10. A. Miller, C. Wei, A.G. Gibson, Comp. Part A., 27, 49-56 (1996).

11. H. Ben Brahim, A. Kallel, Mater. Chem. Phys., 114, 584-587 (2009).

12. S. Tiwari, J. Bijwe, Procedia Technol., 14, 505-512 (2014).

13. A.M. Díez-Pascual, M. Naffakh, C. Marco, M.A. Gómez-Fatou, G.J. Ellis, Curr. Opin. Solid State Mater. Sci., 18, 62-80 (2014).

14. U.A. Samad, M.A. Alam, A. Chafidz, S.M. Al-Zahrani, N.H. Alharthi, Prog. Org. Coatings, 119, 109-115 (2018).

15. I.A. Akpinar, K. Gültekin, S. Akpinar, H. Akbulut, A. Ozel, Compos. Part B Eng., 110, 420-428 (2017).

16. W. Zielecki, A. Kubit, T. Trzepieciński, U. Narkiewicz, Z. Czech, Int. J. Adhes. Adhes., 73, 16-21 (2017).

17. P. Jojibabu, G.D.J. Ram, A.P. Deshpande, S.R. Bakshi, Polym. Degrad. Stab., 140, 8494 (2017).

18. A. Godara, et al., Compos. Sci. Technol., 70, 1346-1352 (2010).

19. H.D. Nguyen-Tran, V.T. Hoang, V.T. Do, D.M. Chun, Y.J. Yum, Materials (Basel)., 11, (2018).

20. C. Chen, Y. Li, Y. Gu, M. Li, Z. Zhang, Mater. Des., 127, 15-21 (2017).

21. U.E.A. Nekliudova, A.S. Semenov, B.E.Melnikov, S.G. Semenov, Mag. Civ. Eng., 47

(3), 25-39 (2014)

22. A. Snegirev, E. Kuznetsov, E. Markus, Fire Saf. J., 93, 74-83 (2017)

23. S.N. Yakovlev, V.L. Mazurin, Mag. Civ. Eng., 74 (6), 53-60 (2017) 
24. R.I. Ableev, I.V. Baranets, S.K. Kurlyand, A.N. Zabelina, A.S. Ramsh, S.A. Kilin, N.V. Sirotinkin, Int. Polym. Sci. Technol., 44 (6), T15-T20 (2017)

25. J. Schäfer, O. Stolyarov, R. Ali, C. Greb, G. Seide, T. Gries, J. Ind. Text., 45 (6), 16611673 (2016)

26. M.V. Lopatin, O.G. Rumba, Teoriya i Praktika Fizicheskoy Kultury, (2015)

27. A. Tonitzki, A.N. Skvortsova, T.S. Koltsova, S.V. Ganin, M.A. Danilova, A.I. Shamshurin, St. Petersburg State Polytechnic University Journal of Engineering Science and Technology, 3(249), 81-88 (2016). 